\title{
Implementation of bundled interventions greatly decreases deep sternal wound infection following cardiovascular surgery
}

\author{
Ken Miyahara, MD, Akio Matsuura, MD, Haruki Takemura, MD, Shinichi Mizutani, MD, \\ Shunei Saito, MD, and Masashi Toyama, MD
}

\begin{abstract}
Objective: Surgical site infection (SSI), particularly deep sternal wound infection (DSWI), is a serious complication after cardiovascular surgery because of its high mortality rate. We evaluated the effectiveness of an SSI bundle to reduce DSWI and identify the risk factors for DSWI.
\end{abstract}

\begin{abstract}
Methods: During the period January 2004 to February 2012, 1374 consecutive patients undergoing cardiovascular surgery via sternotomy were included. The cohort was separated into periods from January 2004 through February 2007 (period I, 682 patients) and March 2007 through February 2012 (period II, 692 patients). During period II, all preventive measures for DSWI were completed as an SSI bundle. We compared the DSWI rate between the 2 periods. Univariate and multivariate analyses were performed for the entire period to identify the risk factors for DSWI.
\end{abstract}

Results: DSWI occurred in 13 patients $(1.9 \%)$ during period I and in 1 patient $(0.14 \%)$ during period II. The DSWI rate during period II was significantly decreased by $93 \%$, compared with period I $(P=.001)$. Independent risk factors for DSWI included obesity (odds ratio [OR], 3.4; 95\% confidence interval [CI], 1.00-11.75; $P=.049$ ), the use of 4 sternal wires (OR, $8.2 ; 95 \% \mathrm{CI}, 1.39-48.14 ; P=.020)$, long operative time (OR, $4.4 ; 95 \%$ CI, 1.20-16.23; $P=.026$ ), and postoperative renal failure (OR, 9.0; 95\% CI, 2.44-33.30; $P=.001$ ).

Conclusions: Complete implementation of simple multidisciplinary prevention measures as a bundle can greatly decrease the incidence of DSWI. (J Thorac Cardiovasc Surg 2014;148:2381-8)

See related commentary on pages $2388-9$.

Surgical site infection (SSI), particularly deep sternal wound infection (DSWI), is a serious complication after cardiovascular surgery. Although the incidence of DSWI is low, $0.13 \%$ to $4 \%,{ }^{1-6}$ the mortality rate ranges from $7 \%$ to as high as $47 \%{ }^{4,7,8}$ DSWI also prolongs hospital stays, ${ }^{6,7}$ increases costs, ${ }^{6,7}$ undermines patient and family satisfaction, ${ }^{7}$ and discourages surgeons and nursing staff. Because multiple factors contribute to DSWI, a multifaceted approach is essential to prevent it. Recently, implementation of evidence-based bundled interventions has decreased the number of SSIs. ${ }^{9,10}$ To reduce DSWI, we introduced and implemented a specific set of actions (ie, bundle) of infection control measures. In this study, we compared the DSWI rate before and after a bundle introduction to evaluate the effectiveness of this

\footnotetext{
From the Division of Cardiovascular Surgery, Ichinomiya Municipal Hospital, Ichinomiya, Aichi, Japan.

Disclosures: Authors have nothing to disclose with regard to commercial support. Received for publication Jan 19, 2014; revisions received March 15, 2014; accepted for publication April 4, 2014; available ahead of print June 3, 2014.

Address for reprints: Ken Miyahara, MD, Division of Cardiovascular Surgery,

Ichinomiya Municipal Hospital, 2-2-22 Bunkyo, Ichinomiya, Aichi 491-8558,

Japan (E-mail: medical.miyahara@nifty.com).

$0022-5223 / \$ 36.00$

Copyright (c) 2014 by The American Association for Thoracic Surgery

http://dx.doi.org/10.1016/j.jtcvs.2014.04.005
}

method. We also identified the most significant risk factors of DSWI.

\section{METHODS \\ Study Design}

This study is a retrospective, nonrandomized review of all patients who underwent cardiovascular surgery via median sternotomy between January 2004 and February 2012 at our institution. A total of 1374 patients were reviewed. During the study period in October 2010, due to hospital merger and acquisition, our team was transferred from Aichi Cardiovascular and Respiratory Center to the hospital we are at now, which had not been performing cardiovascular surgery. This hospital merger was approved by the Japan Cardiovascular Surgery Database Organization and the 2 hospitals were regarded as a serial institution. The institutional review board at both hospitals approved the study.

The cohort was separated into periods from 2004 through February 2007 (period I, $\mathrm{n}=682$ ) and March 2007 through February 2012 (period II, $\mathrm{n}=692$ ). During period II, all preventive measures for DSWI were completed as a SSI bundle consisting of 19 items, including pre-, intra-, and postoperative infection control measures (Table 1). We compared the DSWI rate between the 2 periods. Univariate and multivariate analyses were also performed for the entire period to identify the DSWI risk factors. In our study, DSWI was defined according to the guidelines of the Centers for Disease Control and Prevention (CDC). ${ }^{11}$ SSIs are classified as being either incisional or organ/space. Organ/space SSIs involve any part of the anatomy (eg, organ or space) other than the surgical incision and at least 1 of the following: purulent drainage, microorganisms, an abscess or other evidence of infection, or diagnosis by a surgeon or attending physician. DSWI corresponds to an organ/space SSI. Patients were followed for 1 year postoperatively. Due to high rates of wound infection, patients with delayed sternal closure have often been excluded from this type of study ${ }^{3}$; however, we included these high-risk patients to verify the effectiveness of our measures. 


$$
\begin{aligned}
& \text { Abbreviations and Acronyms } \\
& \qquad \begin{aligned}
\mathrm{BG}= & \text { blood glucose } \\
\mathrm{CDC}= & \text { Centers for Disease Control and } \\
& \text { Prevention } \\
\mathrm{DSWI}= & \text { deep sternal wound infection } \\
\mathrm{MRSA}= & \text { methicillin-resistant Staphylococcus } \\
& \text { aureus } \\
\text { SSI }= & \text { surgical site infection }
\end{aligned}
\end{aligned}
$$

\section{Surgical Management}

Surgical techniques were standardized with no significant operative differences between surgeons. The skin was incised with a scalpel and the presternal layers with electrocautery. After sternotomy, hemostasis was achieved with bone wax and electrocautery. The thymus and pericardium were incised using electrocautery. Postoperative hemostasis was achieved. Silicone chest tubes (19F) were inserted. In addition, temporary epicardial pacing wires were inserted. The sternum was reapproximated with stainless steel wires in a simple cerclage fashion. The number of wires used was increased from 4 to 6 after 2006 for stronger sternal fixation. Abdominal and presternal muscle layers were closed in a simple interrupted technique using 0 coated, braided nylon nonabsorbable sutures. Subcutaneous tissue and dermis were closed using 3-0 and 4-0 continuous absorbable monofilament sutures, respectively.

\section{Infection Control Measures}

Patients undergoing elective surgery were screened for nasal carriage of methicillin-resistant Staphylococcus aureus (MRSA) at the outpatient clinic and if positive, mupirocin ointment was used for 3 days or more.

Patients were advised to shower or bathe with a plain soap (not an antiseptic agent) on the day before the operative day if possible. Body hair was removed, when necessary, using electric clippers after induction of anesthesia immediately preoperatively.

All operative sites were cleaned and disinfected with chlorhexidinealcohol solution $(0.5 \%$ chlorhexidine gluconate in $77 \%$ ethanol solution) with nonsterile gloves. This procedure was repeated 3 to 4 times as with a lacquer coating, with the last coat applied using sterile gloves. Finally, 10\% povidone-iodine was applied to the skin using several pieces of cellulose sponge. At least 2 minutes later, adhesive iodophor-impregnated plastic incision drapes were applied to all surfaces of the operative field.

Surgical hand antisepsis was as follows: the 2-stage procedure or waterless procedure was adopted according to staff preference. Afterward, chlorhexidine-alcohol solution $(0.2 \%$ chlorhexidine gluconate in $80 \%$ ethanol solution) was applied.

All members of the operating team were wearing 2 pairs of gloves (ie, double-gloving) during the operation and outer gloves were changed regularly. Regardless of glove puncture, gloves were changed routinely after such critical procedures as draping the patient, scratching the bone wax, harvesting the graft, tying the suture of the prosthetic valve, and sternal closure (scheduled glove change).

Cefazolin was used for antimicrobial prophylaxis against SSI. An initial dose of $1 \mathrm{~g}$ was given within 30 minutes of the skin incision and the dose was repeated for every 4 hours of additional surgical time. For MRSA carriers ( $1 \%$ of this series), 1 dose of $1 \mathrm{~g}$ vancomycin was added, which started in the ward, was continued for 1 hour, and was completed within 1 hour before skin incision. In all cases, prophylactic antibiotics were limited to intraoperative use only.

Before sternal closure, the pericardial cavity and mediastinum were washed with $1000 \mathrm{~mL}$ normal saline. After closing the sternal and abdominal muscle layers, the wound was also washed with $500 \mathrm{~mL}$ normal saline using a bulb syringe.
Postoperatively, the incision was covered for 2 days with a sterile gauze under a larger elastic adhesive gauze. On the second postoperative day, the gauze was exchanged for a transparent hydrocolloid dressing that was left on for 5 days. On the seventh postoperative day, the dressing was removed and the patient was permitted to shower or bathe. Aseptic or antibiotic agents were not applied to the wound at any time. The wound was visually inspected through the transparent dressing by a cardiovascular surgeon daily.

Steroids have been used routinely for years. A single shot of 1500-mg methylprednisolone was administered to patients before cardiopulmonary bypass. However, since April 2006, the final year in period I, steroids were not administered except in either hypothermic circulatory arrest surgery or in patients who had received steroid therapy preoperatively.

Blood glucose (BG) was checked repeatedly intra- and postoperatively. If the $B G$ value was $>140 \mathrm{mg} / \mathrm{dL}$, continuous insulin therapy was initiated. Postoperative BG levels were checked every 1 to 4 hours. Insulin infusion was continued for at least 2 postoperative days or throughout the intensive care unit stay. After discharge from the intensive care unit or when oral feeding was initiated, intravenous insulin was transitioned to a slidingscale-guided intermittent subcutaneous insulin injection (target BG level, $<150 \mathrm{mg} / \mathrm{dL}$ ), which was continued to at least the seventh postoperative day.

After surgery, the fractional inspired concentration of oxygen was increased to $100 \%$. During at least the first 2 hours postoperatively, fractional inspired concentration of oxygen was kept above $80 \%$ regardless of the partial pressure of oxygen in arterial blood.

\section{Statistical Analysis}

Statistical analysis was performed using SPSS version 21.0 (IBM-SPSS Inc, Armonk, NY). Data are expressed as means \pm standard deviation for continuous variables and percentages for categorical variables. For comparison of continuous variables, Student $t$ test or the Mann-Whitney $U$ test was used, depending on the normality of the data. Categorical variables were compared using $\chi^{2}$ or Fisher exact test. Univariate analysis and multivariate logistic regression analyses were used to determine risk predictors of DSWI. The variables used for univariate analysis are listed in Table 2, except the numbers of patients, wound infections, and deaths. The threshold of the 75th percentile was used to categorize continuous variables.

Variables with a $P$ value $<.05$ by univariate analysis were included in the final multivariable model.

\section{RESULTS}

The clinical characteristics and surgical data of the period I and period II cohorts are listed in Table 2. The patients during period I were more likely to be obese and current smokers, were more likely to have advanced symptoms and to have had nonelective surgery, were more likely to have undergone coronary artery bypass grafting, were less likely to have hyperlipidemia, and were less likely to have a family history of peripheral vascular disease or aortic surgery than those in the period II cohort. The average duration of operation, cardiopulmonary bypass, and aortic crossclamp time were all significantly shorter in period I patients. The incidence of intraoperative steroid use was higher in period I patients. Most patients in period I received 4 sternal wires, whereas 5 or 6 wires were used in period II patients. During period II, no patient had shaved the previous day and all patients received $\geq 80 \%$ oxygen. Patients in period I required a longer intensive care unit stay. The hospital 
TABLE 1. Specific actions (bundles) implemented to reduce/eliminate surgical site infection

Preoperative

Nasal screening for MRSA

Intranasal mupirocin ointment for MRSA carriers

Intraoperative

Hair clipping immediately before the operation, if necessary

Surgical hand antisepsis: hand rubbing with $0.2 \%$ chlorhexidine-alcohol solution

Patient skin preparation: $0.5 \%$ chlorhexidine-alcohol solution applied repeatedly 3 to 4 times, as with a lacquer coating, with the last coat applied using sterile gloves. Finally, $10 \%$ povidone-iodine applied to the skin using several pieces of cellulose sponge.

Adhesive iodophor-impregnated plastic incise drapes applied to all surfaces of the operative field

Administration of prophylactic antibiotics (1 g CEZ) $30 \mathrm{~min}$ before the skin is incised

Readministration of prophylactic antibiotics ( $1 \mathrm{~g} \mathrm{CEZ})$ every $4 \mathrm{~h}$

Discontinuation of prophylactic antibiotics during surgery (intraoperatively only)

Ensure double-gloving for all surgical team members

Scheduled glove change after draping the patient, scratching the bone wax, harvesting the graft, tying the suture of the prosthetic valve, and sternal closure

Check blood glucose levels; if $>140 \mathrm{mg} / \mathrm{dL}$, start insulin infusion

No use of intraoperative steroids, with the exception of aortic surgery with circulatory arrest

Irrigate pericardial cavity, sternum, and wound with saline

Sternal closure using at least 6 stainless steel wires

Postoperative

Maintain control of serum blood glucose levels $<140 \mathrm{mg} / \mathrm{dL}$

Administer $\geq 80 \%$ inspired oxygen for $2 \mathrm{~h}$

Leave wound primarily covered with gauze occlusive dressing for $2 \mathrm{~d}$

Protect wound with transparent hydrocolloid dressing for the next $5 \mathrm{~d}$

MRSA, Methicillin-resistant Staphylococcus aureus; CEZ, cefazolin.

mortality rate was similar between the 2 cohorts. DSWI occurred in 13 patients in period I but only in 1 patient in period II. The incidence rate significantly $(93 \%)$ decreased from $1.9 \%$ to $0.14 \%$ compared with period I $(P=.001)$.

Table 3 summarizes patient characteristics and surgical data for those with DSWI and compares them with data for patients without DSWI. The preoperative patients with DSWI were more likely to be obese, and were more likely to have advanced symptoms, to have had aortic surgery, or to have been shaved the previous day. The average duration of operative and cardiopulmonary bypass were significantly longer in DSWI patients. They were also more likely to have received 4 sternal wires and to have postoperative renal failure, including requiring hemodialysis. The requirement for delayed closure was higher in DSWI patients and they also required longer ventilation support and intensive care unit stay than those without DSWI. The hospital mortality was 8 -fold higher in DSWI patients $(P=.001)$.

Univariate analysis found statistical significance in thoracic aortic surgery, obesity, New York Heart
Association functional class III or IV, hair removal the previous day, sternal closure with 4 wires, long operative time, delayed sternal closure, prolonged ventilation, and postoperative renal failure. Obesity, sternal closure with 4 wires, long operative time, and postoperative renal failure were identified as independent factors using multiple logistic regressions (Table 4).

\section{DISCUSSION}

Although lower rates have been reported recently, the mortality associated with DSWI has not changed for 15 years and it remains a lethal complication. ${ }^{3}$ According to the Japan Adult Cardiovascular Surgery Database, which includes 73,700 cases from 2004 to 2009, the incidence of DSWI is $1.8 \%$, with a mortality of $25.8 \% .^{4}$ In Japan, DSWI prolongs hospital stay 4-fold and increases costs nearly 6-fold.

Excellent surgical technique is widely believed to reduce the risk of SSI. ${ }^{11}$ Such techniques include gentle handling of tissues and maintaining effective hemostasis. Limited use of electrocautery and pinpoint hemostasis for the presternal soft tissues are important to maintain tissue viability. ${ }^{1}$

Nasal carriage of S. aureus increases the risk of SSI in cardiac surgery. ${ }^{11}$ The Society of Thoracic Surgeons practice guidelines series ${ }^{6}$ recommends routine mupirocin administration for all patients in the absence of a documented negative testing for Staphylococcal colonization. This is necessary given the high mortality rates associated with poststernotomy infections caused by S. aureus. ${ }^{6}$ A recent meta-analysis ${ }^{9}$ revealed that nasal decolonization and glycopeptide prophylaxis is effective for preventing SSI caused by gram-positive bacteria after cardiac or orthopedic surgery. Mupirocin is highly effective in eradicating nasal $S$. aureus. However, because $S$. aureus strains can become resistant to mupirocin, restricting its use is recommended. We believe that mupirocin should be used only for MRSA carriers.

Avoiding hair removal is the best way to prevent SSI. ${ }^{11}$ If needed, clipping the morning of the operation has demonstrated lower infection rates. ${ }^{11}$ We have performed clipping after intubation, which is often preferable to avoid embarrassing a patient.

Because the skin is a major source of pathogens that cause SSI, optimization of preoperative skin antisepsis may decrease postoperative infections. Preoperative showering or bathing with antiseptic products is controversial. ${ }^{11,12}$ Regarding cleansing of a patient's skin in the operating room, a recent study demonstrated that chlorhexidinealcohol is superior to povidone-iodine for preventing SSI. ${ }^{13}$ The superiority of chlorhexidine-alcohol is probably related to its more rapid action, persistent activity despite exposure to bodily fluids, and residual effect. ${ }^{13}$ Updated CDC guidelines ${ }^{14}$ describe that the greatest reduction in microbes at 
TABLE 2. Clinical characteristics and surgical data of the period I and period II cohorts

\begin{tabular}{|c|c|c|c|}
\hline Variable & Period I (January 2004-February 2007) & Period II (March 2007-February 2012) & $P$ value \\
\hline No. of patients & 682 & 692 & \\
\hline Age, y & $66.0 \pm 10.2$ & $68.2 \pm 10.1$ & $<.001$ \\
\hline Male sex & $456(66.9)$ & $458(66.2)$ & .819 \\
\hline Family history & $36(5.3)$ & $83(12.0)$ & $<.001$ \\
\hline Obesity & $130(19.1)$ & $103(14.9)$ & .044 \\
\hline Hypertension & $421(61.7)$ & $434(62.7)$ & .739 \\
\hline Diabetes mellitus & $233(34.2)$ & $216(31.2)$ & .250 \\
\hline Hyperlipidemia & $232(34.0)$ & $280(40.5)$ & .014 \\
\hline Preoperative brain damage & $68(10.0)$ & $59(8.5)$ & .402 \\
\hline COPD & $7(1.0)$ & $16(2.3)$ & .091 \\
\hline Peripheral vascular disease & $18(2.6)$ & $95(13.7)$ & $<.001$ \\
\hline Smoking & $348(51.0)$ & $392(56.7)$ & .040 \\
\hline Current smoking & $189(27.7)$ & $143(20.7)$ & .002 \\
\hline Preoperative steroid use & $9(1.3)$ & $8(1.2)$ & .812 \\
\hline IABP & $123(18.0)$ & $100(14.5)$ & .079 \\
\hline NYHA functional class III-IV & $324(47.5)$ & $219(31.7)$ & $<.001$ \\
\hline Preoperative serum creatinine, $\mathrm{mg} / \mathrm{dL}$ & $1.13 \pm 1.28$ & $1.04 \pm 0.88$ & .227 \\
\hline Preoperative renal failure & $36(5.3)$ & $32(4.6)$ & .620 \\
\hline Preoperative renal failure requiring HD & $10(1.5)$ & $16(2.3)$ & .323 \\
\hline IE & $8(1.2)$ & $11(1.6)$ & .645 \\
\hline Nonelective & $231(33.9)$ & $177(25.6)$ & .001 \\
\hline Redo & $26(3.8)$ & $37(5.4)$ & .198 \\
\hline \multicolumn{4}{|l|}{ Category } \\
\hline CABG & $378(55.4)$ & $289(41.8)$ & $<.001$ \\
\hline Valve & $190(27.9)$ & $283(40.9)$ & $<.001$ \\
\hline Aorta & $64(9.4)$ & $93(13.4)$ & .022 \\
\hline Congenital & $24(3.5)$ & $8(1.2)$ & .004 \\
\hline Other & $26(3.8)$ & $19(2.8)$ & .291 \\
\hline Hair removal previous day & $221(32.4)$ & $0(0.0)$ & .000 \\
\hline Intraoperative steroid use & $539(79.0)$ & $103(14.9)$ & $<.001$ \\
\hline \multicolumn{4}{|l|}{ Used sternal wires } \\
\hline 4 & $628(92.1)$ & $0(0.0)$ & .000 \\
\hline 5 & $37(5.4)$ & $102(14.7)$ & $<.001$ \\
\hline 6 & $17(2.5)$ & $590(85.3)$ & $<.001$ \\
\hline Operative time, $\min$ & $358 \pm 116$ & $409 \pm 145$ & $<.001$ \\
\hline Arrest time, min & $114 \pm 44$ & $154 \pm 61$ & $<.001$ \\
\hline $\mathrm{CPB}$ time, $\min$ & $185 \pm 83$ & $231 \pm 107$ & $<.001$ \\
\hline Postoperative $80 \%$ oxygen supply & $424(62.2)$ & $692(100)$ & $<.001$ \\
\hline Postoperative stroke & $19(2.8)$ & $25(3.6)$ & .445 \\
\hline Postoperative serum creatinine, $\mathrm{mg} / \mathrm{dL}$ & $1.47 \pm 1.57$ & $1.45 \pm 1.37$ & .641 \\
\hline Postoperative renal failure & $30(4.4)$ & $31(4.5)$ & .942 \\
\hline Postoperative HD & $16(2.3)$ & $19(2.8)$ & .733 \\
\hline Blood transfusion & $527(77.3)$ & $554(80.1)$ & .211 \\
\hline Early reoperation for bleeding & $35(5.1)$ & $24(3.5)$ & .144 \\
\hline Delayed sternal closure & $2(0.3)$ & $9(1.3)$ & .064 \\
\hline Prolonged ventilation (>24 h) & $233(34.2)$ & $227(32.8)$ & .607 \\
\hline ICU stay, d & $4.2 \pm 4.2$ & $3.7 \pm 4.4$ & $<.001$ \\
\hline Deep sternal wound infection & $13(1.9)$ & $1(0.14)$ & .001 \\
\hline Hospital death & $29(4.3)$ & $23(3.3)$ & .398 \\
\hline
\end{tabular}

the operative site seems to occur with use of chlorhexidine/ alcohol-based products or an iodine povacrylex/alcohol. In the prevention of microbial colonization in central venous catheters, combined skin disinfection with propanol/chlorhexidine followed by povidone-iodine has demonstrated superiority compared with either regimen alone. ${ }^{15}$ We have 
TABLE 3. Characteristics and surgical data for patients with deep sternal wound infection (DSWI) and without DSWI

\begin{tabular}{|c|c|c|c|}
\hline Variable & No DSWI & DSWI & $P$ value \\
\hline No. of patients & 1360 & 14 & \\
\hline Age, y & $67.1 \pm 10.2$ & $68.3 \pm 7.5$ & 657 \\
\hline Male sex & $904(66.5)$ & $10(71.4)$ & .784 \\
\hline Family history & $118(8.7)$ & $1(7.1)$ & 1.000 \\
\hline Obesity & $227(16.7)$ & $6(42.9)$ & .020 \\
\hline Hypertension & $845(62.1)$ & $10(71.4)$ & .587 \\
\hline Diabetes mellitus & 443 (32.6) & $6(42.9)$ & .404 \\
\hline Hyperlipidemia & $505(37.1)$ & $7(50.0)$ & .406 \\
\hline Preoperative brain damage & $125(9.2)$ & $2(14.3)$ & .376 \\
\hline COPD & $22(1.6)$ & $1(7.1)$ & .211 \\
\hline Peripheral vascular disease & $14(1.0)$ & $0(0)$ & .621 \\
\hline Smoking & 731 (53.6) & $9(64.3)$ & .592 \\
\hline Current smoking & $327(24.0)$ & $5(35.7)$ & .346 \\
\hline Preoperative steroid use & $17(1.3)$ & $0(0)$ & 1.000 \\
\hline IABP & $219(16.1)$ & $4(28.6)$ & .263 \\
\hline NYHA functional class III-IV & $532(39.1)$ & $11(78.6)$ & .004 \\
\hline Preoperative serum creatinine, $\mathrm{mg} / \mathrm{dL}$ & $1.08 \pm 1.10$ & $1.09 \pm 0.62$ & .995 \\
\hline Preoperative renal failure & $67(4.9)$ & $1(7.1)$ & .510 \\
\hline Preoperative renal failure requiring HD & $25(1.8)$ & $1(7.1)$ & .236 \\
\hline IE & $18(1.3)$ & $1(7.1)$ & 178 \\
\hline Nonelective & 402 (29.6) & $6(42.9)$ & .376 \\
\hline Redo & $63(4.6)$ & $0(0.0)$ & 1.000 \\
\hline \multicolumn{4}{|l|}{ Category } \\
\hline CABG & $661(48.6)$ & $6(42.9)$ & .791 \\
\hline Valve & 471 (34.6) & $2(14.3)$ & .158 \\
\hline Aorta & $151(11.1)$ & $6(42.9)$ & .003 \\
\hline Congenital & $32(2.4)$ & $0(0.0)$ & 1.000 \\
\hline Other & $45(3.3)$ & $0(0.0)$ & 1.000 \\
\hline Hair removal previous day & $215(15.8)$ & $6(42.9)$ & .016 \\
\hline Intraoperative steroid use & $632(46.5)$ & $10(71.4)$ & .103 \\
\hline \multicolumn{4}{|l|}{ Used sternal wires } \\
\hline 4 & $616(45.3)$ & $12(85.7)$ & .003 \\
\hline 5 & $138(10.2)$ & $1(7.1)$ & 1.000 \\
\hline 6 & 606 (44.6) & $1(7.1)$ & .005 \\
\hline Operative time, $\min$ & $383 \pm 132$ & $488 \pm 216$ & .004 \\
\hline Arrest time, $\min$ & $134 \pm 57$ & $132 \pm 57$ & .907 \\
\hline $\mathrm{CPB}$ time, $\min$ & $207 \pm 98$ & $257 \pm 157$ & .059 \\
\hline Oxygen & $1107(81.4)$ & $9(64.3)$ & .157 \\
\hline Postoperative stroke & $42(3.1)$ & $2(14.3)$ & .071 \\
\hline Postoperative serum creatinine, $\mathrm{mg} / \mathrm{dL}$ & $1.45 \pm 1.46$ & $2.90 \pm 2.13$ & .024 \\
\hline Postoperative renal failure & $54(4.0)$ & $7(50.0)$ & $<.001$ \\
\hline Postoperative HD & $30(2.2)$ & $5(35.7)$ & $<.001$ \\
\hline Blood transfusion & $1070(78.7)$ & $11(78.6)$ & 1.000 \\
\hline Early reoperation for bleeding & $57(4.2)$ & $2(14.3)$ & .119 \\
\hline Delayed sternal closure & $9(0.7)$ & $2(14.3)$ & .005 \\
\hline Prolonged ventilation $(>24 \mathrm{~h})$ & 448 (32.9) & $12(85.7)$ & $<.001$ \\
\hline ICU stay, $\mathrm{d}$ & $3.9 \pm 4.2$ & $12.4 \pm 10.3$ & .008 \\
\hline Hospital stay, d & $26.4 \pm 20.4$ & $96.4 \pm 74.3$ & $<.001$ \\
\hline Hospital death & $48(3.5)$ & $4(28.6)$ & .001 \\
\hline
\end{tabular}

Continuous data are presented as mean \pm standard deviation. Categorical data are presented as the number of patients ( $\%$ ) in each category. $C O P D$, Chronic obstructive pulmonary disease; $I A B P$, intra-aortic balloon pump (preoperative); $N Y H A$, New York Heart Association; $H D$, hemodialysis; $I E$, infectious endocarditis; $C P B$, cardiopulmonary bypass; $I C U$, intensive care unit; $D S W I$, deep sternal wound infection; $C A B G$, coronary artery bypass grafting.

been performing this combined method. Chlorhexidinealcohol is also recommended for decontamination of surgical team members' hands. ${ }^{14}$
Rarely, surgical gloves have pinholes even directly out of the package. According to Japanese industrial standards, pinhole defects are expected in up to 3 of 80 gloves in Japan. This incidence is nonnegligible. Double-gloving significantly reduces the number of perforations ${ }^{16}$ and may reduce the risk of wound contamination from staff members through pinhole or accidental punctures in surgical gloves. ${ }^{11}$ Updated CDC recommendations ${ }^{14}$ request that all members of operative teams double-glove and to change gloves when any perforation is identified. Moreover, our scheduled glove change greatly minimizes the risk of contact between a surgeon's hand and a surgical site.

The optimal duration of prophylaxis has been debated. Many investigators believe that longer durations are needed. ${ }^{17}$ However, the continuation of prophylaxis until all catheters and drains have been removed is not appropriate. ${ }^{17} \mathrm{CDC}$ guidelines ${ }^{11}$ recommend that therapeutic levels of antimicrobial prophylaxis be maintained until, at most, a few hours until after an incision is closed. The Society of Thoracic Surgeons recommends 48 hours or less, based on a study by Harbarth and colleagues. The duration of their study unfortunately depended on the surgeon's preferences, introducing considerable bias. Recently, Mertz and colleagues ${ }^{18}$ used a systematic review and meta-analysis to conclude that longer-term prophylaxis (ie, $\geq 24$ hours) reduced sternal and DSWIs when compared with shortterm antibiotic prophylaxis (ie, $<24$ hours); however, they also commented on the heterogeneity of antibiotic regimens and the risk of bias in the published studies. Actually, in their review, cefazolin was used in only 3 of 12 studies, and the regimens varied. Many studies demonstrate that a single dose or within-24-hours dose is sufficient to optimally reduce SSI. ${ }^{19}$ Prolonged administration of antibiotics carries increased costs, the prospect of drug toxicity, and the development of resistant bacterial strains. ${ }^{7,17} \mathrm{We}$ believe antibiotic prophylaxis given intraoperatively only effectively minimizes infectious complications, as recommended by the CDC. ${ }^{11}$

Wound irrigation is expected to reduce the contaminating microorganisms to below the level required to produce infection. The best solution for irrigation is normal saline. It is safe, cheap, and readily available and does not impair the healing process. ${ }^{20}$ The addition of an antiseptic to the irrigating solution can increase the risk of infection by leading to tissue necrosis. ${ }^{20}$

Moist wound healing is an essential concept. Occlusive dressings, especially hydrocolloid dressings, have demonstrated lower infection rates compared with conventional gauze dressings. ${ }^{21}$ Originally, hydrocolloid dressings were applied immediately after closing an incision. However, we used gauze occlusive dressings first to handle the excess exudate bleeding, and then changed to hydrocolloid dressings. This procedure of delayed hydrocolloid dressings may be controversial. According to CDC guidelines, ${ }^{11}$ 
TABLE 4. Univariate and multivariate analysis results for deep sternal wound infection

\begin{tabular}{|c|c|c|c|c|c|c|}
\hline \multirow[b]{2}{*}{ Characteristic } & \multicolumn{3}{|c|}{ Univariate analysis } & \multicolumn{3}{|c|}{ Multivariate analysis } \\
\hline & OR & $95 \% \mathrm{CI}$ & $P$ value & OR & $95 \%$ CI & $P$ value \\
\hline Aorta & 6.005 & $2.056-17.541$ & .001 & & & \\
\hline Obesity & 3.743 & $1.289-10.892$ & .015 & 3.433 & $1.003-11.750$ & .049 \\
\hline NYHA functional class III-IV & 5.707 & $1.585-20.551$ & .008 & & & \\
\hline Hair removal previous day & 3.994 & $1.372-11.627$ & .011 & & & \\
\hline Use of 4 sternal wires & 7.247 & $1.616-32.502$ & .010 & 8.169 & $1.386-48.141$ & .020 \\
\hline Long operative time & 4.063 & $1.400-11.795$ & .010 & 4.411 & $1.199-16.229$ & .026 \\
\hline Delayed sternal closure & 25.019 & $4.881-128.225$ & $<.001$ & & & \\
\hline Prolonged ventilation & 12.214 & $2.722-54.807$ & .001 & & & \\
\hline Postoperative renal failure & 24.185 & $8.193-71.390$ & $<.001$ & 9.005 & $2.435-33.304$ & .001 \\
\hline
\end{tabular}

$O R$, Odds ratio; $C I$, confidence interval; NYHA, New York Heart Association.

beyond 48 hours it is unclear if an incision closed primarily must be covered by a dressing. Is also unclear if showering or bathing is detrimental to healing. ${ }^{11}$ Antiseptic agents should not be applied to an incision because they have deleterious effects on the many cells that influence wound healing. ${ }^{20}$

Steroids use in cardiovascular surgery remains controversial. $^{22,23}$ Steroids have been routinely used for years in a considerable number of institutions during cardiac surgery with cardiopulmonary bypass. Although steroid therapy is expected to reduce the systemic inflammatory response to cardiopulmonary bypass, the clinical benefit is unclear. Furthermore, steroids may in fact be detrimental with risks including hyperglycemia, impaired wound healing, and increased risk of infection. ${ }^{23}$ Recently, a welldesigned randomized controlled trial ${ }^{24}$ revealed that intraoperative high-dose dexamethasone in adults undergoing cardiac surgery did not reduce the 30-day incidence of major adverse events compared with placebo. The effect of high-dose methylprednisolone for cardiac surgery is being evaluated in a large, ongoing study (the Steroids in Cardiac Surgery trial). ${ }^{24}$ Although we have ceased routine administration of high-dose methylprednisolone, no clinical adverse effects have been shown. If steroids are essential for hypothermic surgery remains an unanswered dilemma.

Perioperative BG control is important to prevent SSI. Maintaining BG levels $\leq 200 \mathrm{mg} / \mathrm{dL}$ using continuous, intravenous insulin infusion has been shown to significantly reduce the incidence of SSI. ${ }^{25}$ In cardiac surgery, target BG levels $<150 \mathrm{mg} / \mathrm{dL}$ are important. ${ }^{26}$ Lipshutz and colleagues ${ }^{27}$ concluded in an evidence-based review that maintaining BG levels $<150 \mathrm{mg} / \mathrm{dL}$ and reducing BG variability in the perioperative period may be both safe and effective. Intensive insulin therapy (target BG, $80-110 \mathrm{mg} / \mathrm{dL}$ ) has been controversial and the effect on SSIs has not been demonstrated. ${ }^{28}$ In consideration of the risk and benefit, we adopted Krinsley's protocol, ${ }^{29}$ which maintains a $\mathrm{BG}<140 \mathrm{mg} / \mathrm{dL}$. Intraoperative BG control in cardiovascular surgery has also been recognized to decrease DSWI. ${ }^{27}$ During both the intra- and postoperative periods hypoglycemia can be avoided by careful management, including BG sampling at 30- to 60-minute intervals if necessary.

Oxidative killing of pathogens by polymorphonuclear leukocytes is the primary mechanism of defense against surgical pathogens. ${ }^{30}$ Several randomized controlled trials ${ }^{31,32}$ have been conducted to assess the effect of perioperative supplemental oxygen administration in reducing the incidence of SSI. However, the results conflicted ${ }^{31,32}$ and results of even meta-analyses can differ according to which trials are included. ${ }^{14,33}$ For adult cardiac surgery, Bustamante and colleagues ${ }^{34}$ concluded that supplemental inspired oxygen does not appear to be clinically useful. Although the effect remains controversial, we recommend this therapy because its cost and associated risks are trivial. Recently updated CDC guidelines ${ }^{14}$ suggest that hyperoxia may be beneficial in various types of surgery.

Many risk factors for DSWI have been proposed; however, risk factors have differed between institutions or studies and are occasionally conflicted. Obesity is a common risk factor for DSWI, ${ }^{5}$ whereas diabetes mellitus and reoperation for bleeding were not significant risk factors in our study. The use of only 4 sternal wires is a significant risk factor, which highlights the importance of sternal stability. ${ }^{2}$ Sternal instability is itself strongly associated with DSWI, ${ }^{2}$ and it is likely that DSWI often develops from a minor skin or subcutaneous infection in the sternal wound and that the infection may spread inward to the mediastinal space if sternal dehiscence occurs. ${ }^{2}$ Tight, secure approximation of the sternum with sufficient sutures will most likely help to reduce infection. ${ }^{35}$ Aggressive antitussive use should be considered $^{2}$ because coughing causes shear stress at the sternal wires and the hemisternal junction. Stress along sternal wires causes cutting of wires and bony fractures. ${ }^{3}$

During the late 1990s, evidence-based medicine was propounded in Japan. In the area of infection control, CDC guidelines ${ }^{11}$ have been recognized as the global standard. However, not all measures to prevent SSI are clearly validated. Some of the routinely used infection control practices cannot be investigated rigorously due to ethical or 
logistic reasons. ${ }^{11}$ Some recommendations are unproved, controversial, or revised by later studies. Various factors are related to infection and it may be difficult to demonstrate if 1 preventive measure is effective on the basis that other factors, including patient status, are equal. Also, the findings from a specific kind of surgery may not be applicable to cardiovascular surgery. Although individual interventions may not directly affect the rate of SSI, implementation of multiple strategies as bundled interventions can reduce the incidence of infection. ${ }^{10} \mathrm{We}$ must choose certain measures to put into practice while considering cost-effectiveness, health insurance systems, and manpower. The key to reducing SSI is the complete implementation of simple, multidisciplinary prevention measures in the pre-, intra-, and postoperative periods. A checklist may help to achieve compliance. ${ }^{14}$ DSWI can potentially be almost eliminated by prevention efforts.

\section{Study Limitations}

Our study has several limitations. First, this study involved a clinical review of patients and a historical difference existed between the 2 groups. Due to the nonrandomized observational design of the study, there were some significant differences in preoperative characteristics. Second, the number of patients was smaller than in previous studies. ${ }^{1-5,8}$ Finally, the small number of patients with DSWI in each period is the principle limitation of this study. ${ }^{5}$ The low incidence of DSWI limited the statistical modeling efforts to identify multivariate predictors of DSWI.

\section{CONCLUSIONS}

Complete implementation of simple multidisciplinary prevention measures can result in a very low incidence of DSWI.

\section{References}

1. Nishida H, Grooters RK, Soltanzadeh H, Thieman KC, Schneider RF, Kim WP. Discriminate use of electrocautery on the median sternotomy incision. A $0.16 \%$ wound infection rate. J Thorac Cardiovasc Surg. 1991;101:488-94.

2. Gardlund B, Bitkover CY, Vaage J. Postoperative mediastinitis in cardiac surgery-microbiology and pathogenesis. Eur J Cardiothorac Surg. 2002;21: 825-30.

3. Matros E, Aranki SF, Bayer LR, McGurk S, Neuwalder J, Orgill DP. Reduction in incidence of deep sternal wound infections: random or real? J Thorac Cardiovasc Surg. 2010;139:680-5.

4. Kubota H, Miyata H, Motomura N, Ono M, Takamoto S, Harii K, et al. Deep sternal wound infection after cardiac surgery. J Cardiothorac Surg. 2013;8:132.

5. Olsen MA, Lock-Buckley P, Hopkins D, Polish LB, Sundt TM, Fraser VJ. The risk factors for deep and superficial chest surgical-site infections after coronary artery bypass graft surgery are different. J Thorac Cardiovasc Surg. 2002;124: $136-45$.

6. Engelman R, Shahian D, Shemin R, Guy TS, Bratzler D, Edwards F, et al. The Society of Thoracic Surgeons practice guideline series: antibiotic prophylaxis in cardiac surgery, Part II: antibiotic choice. Ann Thorac Surg. 2007;83:1569-76.

7. Edwards FH, Engelman RM, Houck P, Shahian DM, Bridges CR. The Society of Thoracic Surgeons Practice Guideline Series: antibiotic prophylaxis in cardiac surgery, Part I: duration. Ann Thorac Surg. 2006;81:397-404.
8. El Oakley RM, Wright JE. Postoperative mediastinitis: classification and management. Ann Thorac Surg. 1996;61:1030-6.

9. Schweizer M, Perencevich E, McDanel J, Carson J, Formanek M, Hafner J, et al. Effectiveness of a bundled intervention of decolonization and prophylaxis to decrease Gram positive surgical site infections after cardiac or orthopedic surgery: systematic review and meta-analysis. BMJ. 2013;346:f2743.

10. Thompson KM, Oldenburg WA, Deschamps C, Rupp WC, Smith CD Chasing zero: the drive to eliminate surgical site infections. Ann Surg. 2011; 254:430-6.

11. Mangram AJ, Horan TC, Pearson ML, Silver LC, Jarvis WR. Guideline for prevention of surgical site infection, 1999. Hospital Infection Control Practices Advisory Committee. Infect Control Hosp Epidemiol. 1999;20: 250-80.

12. Webster J, Osborne S. Preoperative bathing or showering with skin antiseptics to prevent surgical site infection. Cochrane Database Syst Rey 2007; CD004985.

13. Darouiche RO, Wall MJ Jr, Itani KM, Otterson MF, Webb AL, Carrick MM, et al Chlorhexidine-alcohol versus povidone-iodine for surgical-site antisepsis. N Engl J Med. 2010;362:18-26.

14. Alexander JW, Solomkin JS, Edwards MJ. Updated recommendations for control of surgical site infections. Ann Surg. 2011;253:1082-93.

15. Langgartner J, Linde HJ, Lehn N, Reng M, Schölmerich J, Glück T. Combined skin disinfection with chlorhexidine/propanol and aqueous povidone- iodine reduces bacterial colonisation of central venous catheters. Intensive Care Med. 2004;30:1081-8.

16. Tanner J, Parkinson H. Double gloving to reduce surgical cross-infection. Cochrane Database Syst Rev. 2006;CD003087.

17. Dellinger EP, Gross PA, Barrett TL, Krause PJ, Martone WJ, McGowan JE Jr, et al. Quality standard for antimicrobial prophylaxis in surgical procedures. Clin Infect Dis. 1994;18:422-7.

18. Mertz D, Johnstone J, Loeb M. Does duration of perioperative antibiotic prophylaxis matter in cardiac surgery? A systematic review and meta-analysis. Ann Surg. 2011;254:48-54.

19. Bratzler DW, Houck PM. Antimicrobial prophylaxis for surgery: an advisory statement from the National Surgical Infection Prevention Project. Clin Infect Dis. 2004;38:1706-15.

20. Cervantes-Sánchez CR, Gutiérrez-Vega R, Vázquez-Carpizo JA, Clark P, AthiéGutiérrez C. Syringe pressure irrigation of subdermatic tissue after appendectomy to decrease the incidence of postoperative wound infection. World $J$ Surg. 2000;24:38-42.

21. Hutchinson JJ, MuGuckin M. Occlusive dressings: a microbiologic and clinical review. Am J Infect Control. 1990;18:257-68.

22. Kouchoukos NT, Blackstone EH, Hanley FL, Kirklin JK. Hypothermia, circulatory arrest, and cardiopulmonary bypass. In: Kouchoukos NT, Blackstone EH, Hanley FL, Kirklin JK, eds. Kirklin/Barratt-Boyes cardiac surgery. 4th ed. Philadelphia: W.B. Saunders Company; 2012. 86.

23. Chaney MA, Durazo-Arvizu RA, Nicolov MP, Bakhos M. Methylprednisolone does not benefit patients undergoing coronary artery bypass grafting and early tracheal extubation. J Thorac Cardiovasc Surg. 2001;121:561-9.

24. Dieleman JM, Nierich AP, Rosseel PM, van der Maaten JM, Hofland J, Diephuis JC, et al. Intraoperative high-dose dexamethasone for cardiac surgery: a randomized controlled trial. JAMA. 2012;308:1761-7.

25. Furnary AP, Zerr KJ, Grunkemeien GL, Starr A. Continuous intravenous insulin infusion reduces the incidence of deep sternal wound infection in diabetic patients after cardiac surgical procedures. Ann Thorac Surg. 1999;67: 352-60.

26. Furnary AP, Wu Y, Bookin SO. Effect of hyperglycemia and continuous intravenous insulin infusions on outcomes of cardiac surgical procedures: the Portland Diabetic Project. Endocr Pract. 2004;10(Suppl 2):21-33.

27. Lipshutz AK, Gropper MA. Perioperative glycemic control: an evidence-based review. Anesthesiology. 2009;110:408-21.

28. Kao LS, Meeks D, Moyer VA, Lally KP. Peri-operative glycaemic control regimens for preventing surgical site infections in adults. Cochrane Database Sys Rev. 2009;CD006806.

29. Krinsley JS. Effect of an intensive glucose management protocol on the mortality of critically ill adult patients. Mayo Clin Proc. 2004;79:992-1000.

30. Allen DB, Maguire JJ, Mahdavian M, Wicke C, Marcocci L, Scheuenstuhl H, et al. Wound hypoxia and acidosis limit neutrophil bacterial killing mechanisms. Arch Surg. 1997;132:991-6.

31. Greif R, Akça O, Horn EP, Kurz A, Sessler DI. Supplemental perioperative oxygen to reduce the incidence of surgical-wound infection. Outcomes Research Group. N Engl J Med. 2000;342:161-7. 
32. Pryor KO, Fahey TJ III, Lien CA, Goldstein PA. Surgical site infection and the routine use of perioperative hyperoxia in a general surgical population. A randomized controlled trial. JAMA. 2004;291:79-87.

33. Al-Niaimi A, Safdar N. Supplemental perioperative oxygen for reducing surgical site infection: a meta-analysis. J Eval Clin Pract. 2009;15:360-5.
34. Bustamante J, Tamayo E, Alvarez FJ, García-Cuenca I, Flórez S, Fierro I, et al. Intraoperative $\mathrm{PaO}_{2}$ is not related to the development of surgical site infections after major cardiac surgery. J Cardiothorac Surg. 2011;6:4.

35. Tector AJ, Amundsen S, Schmahl TM, Kress DC, Peter M. Total revascularization with T grafts. Ann Thorac Surg. 1994;57:33-9.

\title{
EDITORIAL COMMENTARY
}

\section{An ounce of prevention is worth a pound of cure}

\author{
Kevin L. Greason, MD
}

See related article on pages 2381-8.

Surgical site infection remains an unfortunate occurrence of cardiac surgery with deep sternal wound infection (eg, mediastinitis) being the most feared. The good news is that the prevalence is low, around $0.5 \%$ to $5 \%$; the bad news is that the associated mortality may be high, around $40 \%$. The financial cost must also be considered; the attributable cost for a procedure complicated by deep sternal wound infection may be as much as 3 times greater than that of an uncomplicated procedure. It is no longer acceptable to view surgical site infection as a possible risk and unfortunate outcome of a surgical procedure, especially because implementation of effective infection prevention programs, such as those presented here, may significantly reduce the occurrence of infection. ${ }^{1,2}$

In this article of the Journal of Thoracic and Cardiovascular Surgery, Miyahara and colleagues ${ }^{2}$ report a significant reduction in the prevalence of deep sternal wound infection after the implementation of a specific set of simple multidisciplinary prevention measures (the bundle). ${ }^{2}$ The success of the bundle lies in that it recognizes that multiple factors contribute to deep sternal wound infection and that multiple modalities of treatment are essential to prevent it. The factors that contribute to infection and the modalities of treatment may be collected into 2 simple and convenient assemblages: patient characteristics and operative issues. ${ }^{3}$

From the Division of Cardiovascular Surgery, Department of Surgery, Mayo Clinic, Rochester, Minn.

Disclosures: Author has nothing to disclose with regard to commercial support.

Received for publication Sept 17, 2014; accepted for publication Sept 17, 2014

Address for reprints: Kevin L. Greason, MD, Mayo Clinic, 200 First St SW, Rochester, MN 55905 (E-mail: greason.kevin@ mayo.edu).

J Thorac Cardiovasc Surg 2014;148:2388-9

0022-5223/\$36.00

Copyright (C) 2014 by The American Association for Thoracic Surgery

http://dx.doi.org/10.1016/j.jtcvs.2014.09.051
In cardiac surgery, patient characteristics possibly associated with an increased risk of surgical site infection include coincident remote site bacterial colonization, diabetes, systemic steroid use, obesity, and the extremes of age. The most modifiable of these risk factors is that of coincident preoperative nares colonization with Staphylococcus aureus. Such carriage is a powerful independent risk factor for surgical site infection after cardiac operations. Mupirocin ointment is an effective topical agent against this hazard, and treatment is indicated for all patients. Current consensus is that broad use of the antibiotic is unlikely to result in mupirocin resistance because treatment courses are brief.

Operative issues may be further categorized into interventions that occur during specific periods: intraoperative and postoperative. The intraoperative infection control measures recommended by the Centers for Disease Control and Prevention include hair clipping immediately before the operation, antimicrobial prophylaxis in accordance with evidence-based standards and guidelines, and use of appropriate antiseptic agents and techniques for skin preparation. $^{3}$ Miyahara and colleagues ${ }^{2}$ add to the list additional maneuvers that include the use of an iodophorimpregnated drape, double-gloving for all surgical team members, scheduled glove changes, minimization of intraoperative steroids, pericardial irrigation, and secure sternal closure with at least 6 wires.

Best practices of postoperative infection control include measures nicely outlined by the Centers for Disease Control and Prevention ${ }^{3}$ and Miyahara and colleagues. ${ }^{2}$ These include the restoration of normothermia, maintenance of control of serum blood glucose levels at less than $140 \mathrm{mg} / \mathrm{dL}$, administration of greater than $80 \%$ inspired oxygen for 2 hours, continuation of antibiotics according to evidence-based standards and guidelines, and wound coverage with a sterile, dry dressing for at least 48 hours. ${ }^{2,3}$ Miyahara and colleagues ${ }^{2}$ go further to recommend changing the wound dressing to a transparent hydrocolloid dressing for the next 5 days. 